\title{
Flexible Integration of Service Suppliers in Collaborative Service Procurement Networks
}

\author{
Maik Herfurth $^{1}$, Thomas Schuster ${ }^{1}$, and Peter Weiß ${ }^{2}$ \\ ${ }^{1}$ FZI Forschungszentrum Informatik, Haid-und-Neu-Str. 10-14, \\ 76131 Karlsruhe, Germany \\ \{herfurth, schuster\}@fzi.de \\ 2 ISS International School of Service Management, Hans-Henny-Jahnn-Weg 9, \\ 22085 Hamburg, Germany \\ weiss@iss-hamburg.de
}

\begin{abstract}
A new conceptual design for service procurement networks may surpass existing limitations and bottlenecks. Thereby efficiency can be improved and transaction costs be reduced. To overcome existing limitations a design approach is presented that supports enterprise application integration based on master data and company-wide business process integration. Master data is harmonized with standardized data types and service-oriented architectures (SOA). eBuS-XML is introduced, in the proposed solution it serves as service-specific XML-based library for transaction data types, storage and integration of service e-procurement order processing.
\end{abstract}

Keywords: Collaborative Procurement Networks, Service Procurement, B2B Integration, Service-Oriented Architecture (SOA), eBuS-XML.

\section{Introduction}

Service e-procurement is an important subject in the field of e-business. Service suppliers and service supplicants cooperate in collaborative networks [1] [2] as part of service supply chains. In service supply chains, the major characteristics of services intangibility, interaction and individuality - have most influence on service eprocurement practice. E-business solutions and standards today merely reflect specific elements and variables of services. Despite of recent advancements and innovations in ICT, electronic service procurement solutions are often lacking efficiency. Typical observations are [3]:

i) service procurement processes are not fully integrated in current IT systems

ii) electronic data exchange is only supported partially and

iii) integration solutions are often not adequately aligned with peculiarities of service processes and logic being tailored primarily to the needs of material procurement.

Consequently, collaborative service processes suffer from various media breaks and are thus source of increasing costs, occurring failures and manual error handling. Service procurement is a niche market of specialized IT vendors offering 
individualized, highly specialized IT tools supporting service-related business logic and transactions [4]. In this paper, we conceptualize the design and flexible solutions based on flexible service-oriented architectures.

\section{Service Procurement and Collaborative Networks}

Service procurement processes are still a source of high costs to companies due to its perceived complex and heterogeneous purchasing processes. Service procurement networks consist of service consumers, service producers and intermediate parties. Service producers (contractors) are mostly small and medium-sized companies. Service consumers (ordering party) are bigger companies while intermediate parties are supporting medium-sized companies for service consumers and producers. Standards are seen as "[...] valuable basis for networking within individual industry sectors" [5]. A companies' value is more and more determined through its ecosystem and ability to interact with business partners on the basis of electronic services or machine-to-machine transactions [5]. Companies trading with each other use often similar software, or vendors determine formats and often industry sector standards. Service procurement requires specific collaborative services which are not adequately supported by IT applications and electronic services yet. Large companies typically support up to now service-related business processes through individually customized web-based information systems [6].

\subsection{Collaborative Business Processes}

Collaborative business processes have a major influence on the conceptual design of service e-procurement.

Service procurement processes seem to have the same phases as material processes. But a major difference of service procurement processes is in process

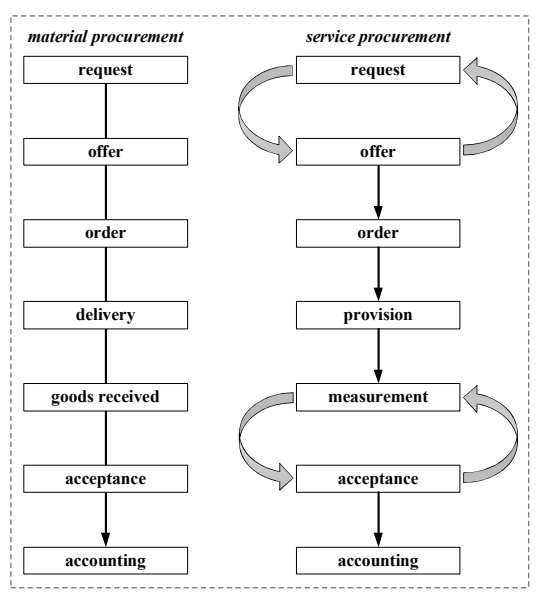

Fig. 1. Interaction Cycles of Service Procurement 
phases offer and measurement, which are characterized by a differing logic through more interactions between actors that result in process cycles [3] (see fig. 1). Process cycles derive from the interaction of service consumers and service producers during the offer phase: both actors have to agree on the specification of the service provision. In the measurement phase, the service consumer and the service producer negotiate the bill of quantities for the accounting. The degree of business process integration influences significantly effectiveness and efficiency of service-related procurement transactions. The effective integration of company-wide business processes along the service value chain is still immature. This motivates the development of a flexible enterprise application integration solution. Large enterprises have started to standardize collaborative business processes with their suppliers, often using purchasing platforms (Supplier Self Services) which are highly integrated in their ERP systems [5].

\section{Solution and Evaluation Approach}

In order to surpass the described problems and challenges for service e-procurement, service procurement networks were evaluated by looking at a set of real life use cases (18 in total). Internal and company-wide processes were analyzed with regard to document and data flow, as well as used IT-systems. For the conceptual design of electronic services for service procurement networks, two essential elements were identified: (1) service business processes (supporting required interaction phases) and (2) flexible IT systems. The designed solutions support service-oriented transactions through standardized interfaces, data integration and harmonized service master data. Master data is seen to "[...] bring a strong competitive advantage" [5]. The analyzed use case scenarios represent typical sector-specific value chain constellations from the area of industrial maintenance services and are related to facility management, industry waste disposal, asset management, cleaning and renewable energies (photovoltaic plants). For analysis of the selection of use cases a systematic approach was applied (see fig. 2).

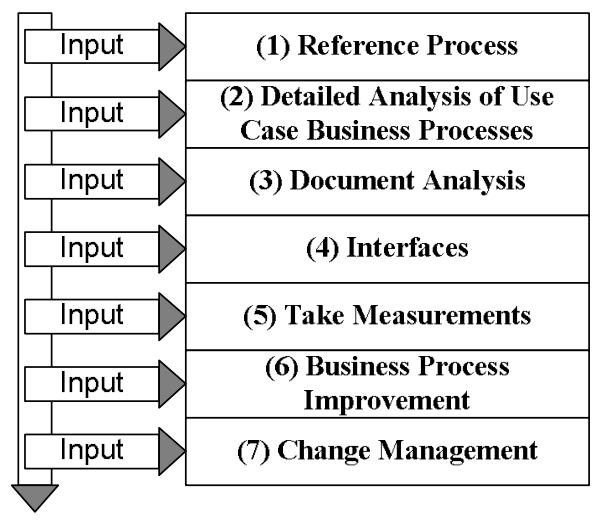

Fig. 2. Systematic Analysis Approach 
A detailed analysis of the business processes starts with reference process modeling (1) in order to realize mayor differences and discrepancies of process instances of selected use cases. The reference process model was presented in [4]. The reference process model defines typical collaborative interfaces between contractors and ordering parties. In a detailed analysis of use cases (2), the business processes are analyzed, media breaks are marked and scrutinized, redundant activities like repeated manual input of business data in company's IT-system. An analysis of documents (3) aims at better understanding of information flows in the service network. Existing interfaces (4) connecting the various IT-systems were looked at and data flows were analyzed in depth. Internal and company-wide processes were assessed to measure processing time of transactions and processes, total cycle time for processing service orders and required amount of man-hours and days (5). Finally, the results of analysis of realized measurement leads to re-engineering of value or business processes (6) which need to be accompanied by an appropriate change management to achieve required sustainability (7). As a major result yielding from our analysis, a tool box was developed including universal e-business formats and features to be considered and implemented by service procurement systems. The following elements are contained in the tool box: reference modeling of service-related procurement processes, standardized e-business interfaces and transaction formats [3], service classification system [4] and universal service master data (data types in typical transactions) in electronic document exchange and data flow. In the remainder, the support of business process by EAI and SOA are in focus.

\section{Support of Company-Wide Business Processes by EAI and SOA}

Service-oriented Computing (SoC) is emerging as a promising paradigm for enabling flexible interconnection of autonomously developed and operated components within and across organizational boundaries [7]. SoC is a distributed application integration paradigm in which the functionality of existing components is described in a declarative way, new applications can be built by reuse of given functionality. The latter does allow an improved support of changed business processes. Main associated enabling technologies are currently the so called WS-technologies such as SOAP, WSDL, WS-Security and WS-BPEL. These technologies enable declarative service descriptions, publication of these descriptions, description-based service discovery and service reuse. Integration of services can foster the execution of distributed business processes and enhanced business-to-business integration. Major business-tobusiness integration types are point-to-point integration, process based integration and mature $B 2 B$ integration. Process based integration support process management functionality by use of management systems to broke message exchange. The mature B2B integration provides connectivity to trading partner networks, examples are RosettaNet [8], EDI [9] or ebXML [10]. Collaborative networks of services suppliers and services consumers lack the support of flexible company-wide business processes for the planning, specification and the e-procurement of services. A servicespecification support for the company's application integration and servicespecification support of business processes is not support by today's solutions Especially the specification of interaction cycles (see fig. 2) is not supported. 


\subsection{Service Master Data Management}

In procurement networks, a high flexibility in terms of business processes and changing market conditions are decisive for successful trading. IT-Solutions strive concurrently for advanced flexibility and a high level of integration to reduce transaction costs. The service oriented paradigm (SOA) fulfills both criteria. The loosely coupling replaces complex interfaces of individual technologies. Web services offer business functions of applications and hide system specific specifications. SOA defines network-based applications by describing their offered functions with WSDL and using XML for the exchange of XML documents. To enable harmonized document exchange and data flow, the description and specification of industrial services and transaction types need standardization. $e B u S-X M L$ was developed, an XML-based format facilitating standardized transaction data to overcome ambiguous semantics and heterogeneous data type definitions.

Table 1. Requirements for implementing Electronic Procurement Solutions, Business Process Integration and Standardization

\begin{tabular}{|c|c|c|c|c|c|c|c|}
\hline Requirements & Description & $\mathrm{a}$ & $\mathrm{b}$ & $\mathrm{c}$ & $\mathrm{d}$ & $\mathrm{e}$ & $\mathrm{f}$ \\
\hline modularity & $\begin{array}{l}\text { modularity of service position } \\
\text { definitions }\end{array}$ & $\mathrm{x}$ & & & & & $\mathrm{x}$ \\
\hline hierarchy support & hierarchy of service positions & $\mathrm{x}$ & & & $\mathrm{x}$ & & $\mathrm{x}$ \\
\hline linking & linking of service positions & & $\mathrm{x}$ & & $\mathrm{x}$ & & $\mathrm{x}$ \\
\hline hybrid structure & $\begin{array}{l}\text { linkage between service positions } \\
\text { and material }\end{array}$ & & & & & & $\mathrm{x}$ \\
\hline order sequence & $\begin{array}{l}\text { free order sequence of service } \\
\text { positions }\end{array}$ & & & & $\mathrm{x}$ & & $\mathrm{x}$ \\
\hline classification & $\begin{array}{l}\text { classification of material and } \\
\text { services }\end{array}$ & & $\mathrm{x}$ & $\mathrm{x}$ & & & $\mathrm{x}$ \\
\hline position types & $\begin{array}{l}\text { service position and material } \\
\text { position }\end{array}$ & & $\mathrm{X}$ & $\mathrm{x}$ & & & $\mathrm{X}$ \\
\hline contracting & contract references & $\mathrm{x}$ & & & & & $\mathrm{x}$ \\
\hline service identifiers & $\begin{array}{l}\text { service identifier concept for } \\
\text { different roles }\end{array}$ & $(\mathrm{x})$ & & & & & $\mathrm{x}$ \\
\hline external factor & $\begin{array}{l}\text { description and specification of } \\
\text { external factor }\end{array}$ & & & & & & $\mathrm{x}$ \\
\hline document types & $\begin{array}{l}\text { specific document types for } \\
\text { document exchange }\end{array}$ & (x) & $(\mathrm{x})$ & & $(\mathrm{x})$ & & $\mathrm{X}$ \\
\hline $\begin{array}{l}\text { electronic product } \\
\text { catalogue }\end{array}$ & $\begin{array}{l}\text { service positions specification in } \\
\text { electronic product catalogues }\end{array}$ & & & $\mathrm{x}$ & & & $\mathrm{x}$ \\
\hline service specifications & service specification format support & $\mathrm{x}$ & & & & & $\mathrm{x}$ \\
\hline interfaces & $\begin{array}{l}\text { definition of interfaces between } \\
\text { procurement systems }\end{array}$ & & & & & & $\mathrm{x}$ \\
\hline $\begin{array}{l}\text { message types and } \\
\text { interfaces }\end{array}$ & binding of flexible architectures & & & & & & $\mathrm{x}$ \\
\hline
\end{tabular}

eBuS-XML can be understood as an XML-based library of service transaction specific data types for the definition and description of order processing elements especially data transactions, service description and data and application integration. Data transaction elements are transaction documents, service description elements are definitions of service specifications. Electronic catalogues and enterprise application integration is supported through WSDL-based interfaces and message types. 
eBuStrans defines the specific document types for the document exchange between business partners in the ecosystem. Service specifications contain all data required for describing and specifying service positions. The service specification data format enables interoperable and portable service specifications. eBuScat specifies data structures in conformity with existing standards such as BMEcat [11]. eBuSWSDL specifies interfaces and message types for a service-oriented interaction and integration of software packages and IT systems. The format allows and supports interactions of various business scenarios. New product-based services can be offered through third party service suppliers such as condition monitoring, preventive maintenance, spare parts management, etc. based on frame contracts and standardized service catalogues [5]. We analyzed existing standards like GAEB 90, 2000 and GAEB DA XML (a) [12], openTRANS (b) [13], BMEcat (c) [11], (d) UBL [14], ebXML (e) [9]. eBuS-XML (f) tends to overcome existing gaps and weaknesses. In table 1, requirements are defined for relevant data exchange in the context of industrial services. Differences of underlying business data and exchange standards were analyzed for electronic procurement solutions like e-catalogue standards and transaction standards. Based on our defined requirements, $e B u S-X M L$ defines all data types to fulfill derived requirements. $e B u S$-XML focuses on two parts of business communication: harmonized data exchange of service procurement data for transactions and integration of application systems.

\section{Flexible Integration of Supplier and Customers in Collaborative Added Value Networks}

For a flexible integration of suppliers and customers, different integration scenarios can be applied. In a buy side solution scenario, the ordering party provides a portal solution for the interaction and communication for the order processing. Contractors are enabled for login and interact with the ordering party by submitting order processing data and business documents. In most cases, after submitting data, the contractor receives a pdf-document as confirmation. Business processes are characterized by repetitive manual data input into respective IT systems. Electronic market places can be seen as further alternative solution scenario, these are often implemented by portal solutions that offer capabilities for distributive trading. In contrast to buy side solution scenarios, contractors offer their services with sell side solution systems. Based on a buy side solution we developed a service oriented approach to support and improve the integration and interaction with contractors. Based on our reference process model [3], five different services were identified. Four services are directly derived from the reference process and cover different process phases (see table 2). $e B u S W S D L$ is presented as a defined part of the data type library of $e B u S-X M L$ and is partially covered by eBuStrans. It also inherits from eBuScommontypes. eBuSWSDL defines message types based on the transactionoriented document types. The $e B u S-X M L$ library is shown in figure 4 .

In a next step, WSDL specifications for Web Services and the exchange of message types have been defined. Service interfaces and message types are described. Interfaces define portTypes, binding, ports and services. Message types are based on our service specific XML library eBuS-XML. 
Table 2. Web Service types for supporting the Reference Process Model

\begin{tabular}{|c|c|c|}
\hline Web Service & Reference Process Phase & Description \\
\hline Service Specification & $\begin{array}{l}\text { Specification of services } \\
\text { Requisition definition }\end{array}$ & $\begin{array}{l}\text { Configuration and specification of } \\
\text { services and aggregated services }\end{array}$ \\
\hline Request for Quotation & $\begin{array}{l}\text { Offer request } \\
\text { Offer creation } \\
\text { Offer comparison } \\
\text { Offer negotiation }\end{array}$ & $\begin{array}{l}\text { The specification is used for an } \\
\text { offer request and creation of an } \\
\text { offer. Offers can be compared and } \\
\text { negotiated between parties. }\end{array}$ \\
\hline Purchase Order & $\begin{array}{l}\text { Order creation } \\
\text { Order confirmation } \\
\text { Order Measurement } \\
\text { Order acceptance }\end{array}$ & $\begin{array}{l}\text { Orders can be created and } \\
\text { confirmed. Measurement data can } \\
\text { be defined, created and accepted. }\end{array}$ \\
\hline Invoicing & $\begin{array}{l}\text { Invoice and debit note } \\
\text { creation } \\
\text { Payment confirmation }\end{array}$ & $\begin{array}{l}\text { Invoice or debit note can be } \\
\text { defined and exchanged. Payment } \\
\text { to be confirmed. }\end{array}$ \\
\hline Information & Supporting all phases & $\begin{array}{l}\text { Defines additional service } \\
\text { operations for continuous and } \\
\text { complete data exchange }\end{array}$ \\
\hline
\end{tabular}

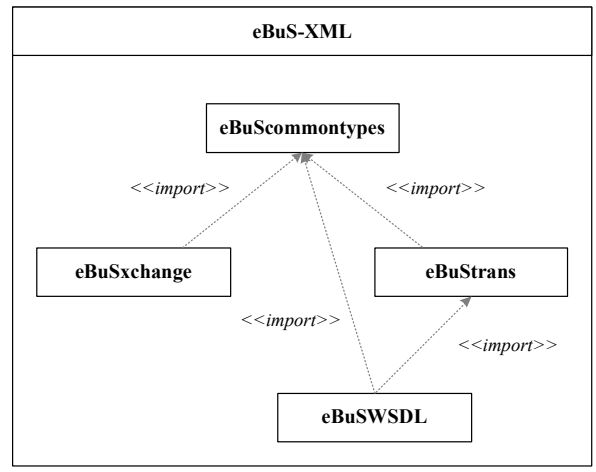

Fig. 3. eBuS-XML library

\section{Conclusion and Outlook}

In this paper, we presented a systematic approach for service procurement in collaborative service procurement networks. In total we analyzed 18 use cases which allowed us to validate the achieved results. Conceptual design for service eprocurement networks with two essential elements could be developed: service business processes and flexible IT systems which adequately support service-oriented transactions through standardized interfaces, data integration and harmonized service master data. A flexible web service architecture designed on basis of specific service business documents for message exchange was proposed. The integration of business processes and master data results in increased efficiency and effectiveness of servicerelated transactions such as order processing. Derived new features of enterprise application solutions fitting requirements of service procurement networks were introduced. We presented XML-based data types called $e B u S-X M L$ aiming at standardization of service-related business transactions as well as flows of data and 
documents. Furthermore, sell side scenario was presented and validated. The paper introduced $e B u S W S D L$ and described WSDL document types and services. Next steps will foresee evaluating the different integration scenarios in real life procurement networks. Yielded results from our research need further validation and will be implemented in pilot applications. Several industry partners indicated their interest to evaluate and validate proposed solution approach and data format based on real life uses cases.

\section{References}

1. Herfurth, M., Meinhardt, A., Schumacher, J., Weiß, P.: eProcurement for industrial maintenance services. In: Camarinha-Matos, L.M., Paraskakis, I., Afsarmanesh, H. (eds.) PRO-VE 2009. IFIP AICT, vol. 307, pp. 361-368. Springer, Heidelberg (2009)

2. Camarinha-Matos, L.M., Paraskakis, I., Afsarmanesh, H. (eds.): PRO-VE 2009. IFIP AICT, vol. 307. Springer, Heidelberg (2009)

3. Herfurth, M., Kern, R., Rudolf, C., Weiß, P.: Reducing the complexity of Services: a new Approach to Service e-Procurement. In: Proceedings of the Multikonferenz Wirtschaftsinformatik MKWI 2010, Göttingen/Germany (2010)

4. Herfurth, M., Weiß, P.: E-Procurement for Industrial Maintenance Services. In: eChallenges 2009, Istambul/Turkey (2009)

5. Kagermann, H., Oesterle, H., Jordan, J.M.: IT-driven Business Models: Global Case Studies in Transformation. Wiley, New Jersey (2011)

6. myOpenFactory, DIN PAS 1074: myOpenFactory 4.0 (2009), http: / /myopenfactory.com/products-myopenfactory.html

7. Alonso, G., Casati, F., Kuno, H., Machiraju, V.: Web Services - Concepts, Architectures and Applications. Springer, Heidelberg (2004)

8. GS1: RosettaNet (2011), http: / / www . rosettanet.org

9. United Nations Economic Commission for Europe: UN/Edifact (2011), http : / / www . unece.org/cefact /

10. UN/CEFACT, OASIS: ebXML (2011), http : / /www . ebxml . org /

11. BME: BMEcat (2011), http: / /www. bmecat . org/deutsch/index . asp?main=Start\&pid=

12. GAEB: GAEB DA XML (2011), http: / / www.gaeb-da-xml. de/

13. Fraunhofer IAO: openTRANS (2011), http: / /www . opentrans . de/

14. OASIS: ebXML (2011),

http://www.oasis open.org/committees/tc_home.php?wg_abbrev=ubl 